\title{
Analisis Keefektifan Penggunaan Filter FIR dan IIR pada Sinyal Pernapasan EMGdi dengan Simulasi MATLAB
}

\author{
Christopher Leonard ${ }^{1}$, Nabila Husna Sabrina ${ }^{2}$, Putu Gandhi Aditya Bayuntara ${ }^{3}$, Yesaya Ariel $^{3}$ \\ ${ }^{1,3}$ Program Studi Teknik Fisika, Universitas Multimedia Nusantara, Tangerang, Indonesia \\ christopher5@student.umn.ac.id \\ ${ }^{2}$ Program Studi Teknik Komputer, Universitas Multimedia Nusantara, Tangerang, Indonesia
}

Diterima 20 Mei 2020

Disetujui 16 Juni 2020

\begin{abstract}
Medical instrumentations are used to retrieve and record signal data in the patient's body such as respiratory signals. The data from the respiratory signal is able to diagnose the patient's respiratory health. Unfortunately, in retrieving signal data, there are noises that interfere with the required signal information. In this article, the signal input will be filtered with two types of filter (FIR filter with window method and IIR filter with pole-zero placement method or bilinear transformation method) and compared their effectiveness to reduce or eliminate the noise signal. Both filters have a cut-off frequency of 50 Hz. The output signal shows that the noise ECG signal is more effective to be eliminated with an FIR filter because of its stability and linear response. Therefore, FIR filter is more recommended being used in EMGdi medical instrumentation for its effectiveness according to Signal-to-Noise Ratio (SNR), execution time, and zero-pole diagram.
\end{abstract}

Index Terms-Bilinear Transformation Method, Digital Filter, Electromyography, Window Method

\section{PENDAHULUAN}

Dalam dunia medis, banyak digunakan alat-alat elektronik yang berguna untuk mengetahui kondisi seseorang. Penggunaan alat-alat elektronik medis tersebut menghasilkan sinyal-sinyal informasi yang diperlukan untuk mendiagnosa maupun memberikan kesimpulan terhadap kesehatan pasien sehingga keakuratan alat pengukuran medis sangat penting. Pada umumnya, sinyal tersebut berupa masukan analog yang kemudian diubah menjadi keluaran digital untuk mempermudah pengolahan dan interpretasi.

Alat-alat elektronik yang ada dalam sebuah ruangan serta ketelitian alat medis yang digunakan menjadi faktor yang akan mempengaruhi keluaran bacaan sinyal yang diinginkan karena terdapat noise. Adanya noise pada sebuah sinyal akan mengganggu pembacaan sehingga data yang diperoleh menjadi tidak akurat. Oleh karena itu, dibutuhkan sebuah filter yang berguna untuk mengeliminasi noise tersebut.

Filter merupakan sebuah perangkat atau proses yang dapat mengeliminasi komponen-komponen sinyal yang tidak diinginkan dari sinyal masukkan [1]. Terdapat beragam jenis filter, namun yang digunakan pada perbandingan dan analisis kali ini adalah filter digital dengan metode low pass filter IIR (Infinite Impulse Response) dan filter FIR (Finite Impulse Response). Pemilihan digital filter sebagai filter sinyal input bertujuan pada tingkat keakurasian dan kepresisian filter [1] serta mampu disimulasikan dalam perangkat lunak MATLAB.

Pada artikel ini akan dikembangkan penggunakan filter IIR pada data sinyal pernapasan EMGdi pernah dilakukan pada [2] dengan membandingkan segi keefektifan filter dengan menggunakan filter FIR. Berdasarkan [3-4] filter FIR mampu menghilangkan noise pada pengaplikasian sinyal ECG karena memiliki properti fasa yang linear dan karakteristik yang stabil serta mampu meningkatkan kecepatan kalkulasi filter sebesar 13,65\%. Oleh karena itu, artikel ini akan mencoba mengaplikasikan penelitian [2] dengan menggunakan filter FIR dan melihat apakah keefektifan filter tersebut juga berlaku ketika diaplikasikan pada sinyal EMGdi dengan menggunakan Signal-to-Noise Ratio (SNR), execution time, serta zero-pole diagram kedua filter.

Data sinyal yang akan digunakan merupakan data sinyal pernapasan EMGdi (Diaphragm Electromyography) dari salah satu subjek dari jurnal [5] dengan periode sampling 0,0005 detik. Sinyal EMGdi merupakan sinyal mentah yang terdiri dari informasi kondisi pernapasan subjek serta sinyal noise ECG (Electrocardiogram). Untuk memisahkan sinyal yang diinginkan serta noise akan dilakukan penyaringan menggunakan filter FIR (window method) dengan cut-off frequency sebesar $50 \mathrm{~Hz}$ serta filter IIR (bilinear transformation method / Pole Zero placement method) dari pendekatan rangkaian 
highpass filter sederhana yang diubah menjadi zdomain dengan cut-off frequency $50 \mathrm{~Hz}$ dan resistor 1 $\Omega$ (besar resistor dan cut-off frequency sudah cukup untuk filter sinyal EMGdi [2]). Penggunaan jenis metode filter FIR dan IIR pada artikel ini tidak dibuktikan keefektifan tiap-tiap jenis filter.

\section{KONSEP DESAIN FILTER}

\section{A. Digital Filter}

Filter digital pada suatu sistem berfungsi untuk mengubah bentuk sinyal, karakteristik amplitudo frekuensi dan/atau fase frekuensi dari sinyal menjadi sinyal yang diinginkan. Tujuan utama dari filter digital adalah untuk mengurangi noise serta mendapatkan informasi dari sinyal [1].

Filter digital merupakan algoritma matematis yang diimplementasikan ke dalam perangkat lunak atau perangkat keras yang menerima masukan sinyal, diolah, dan menghasilkan keluaran sinyal digital dengan bentuk karakteristik sinyal yang diinginkan.

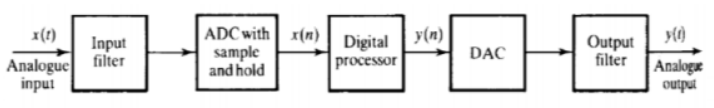

Gambar 1. Diagram blok proses sinyal dari analog input hingga analog output dengan melewati dua filter analog dan digital

\section{B. Finite Impulse Response - Window Method}

Filter FIR memiliki karakteristik linear phase response filter, stabil, serta mudah untuk diimplementasikan ke dalam perangkat keras.

Salah satu metode untuk menghitung koefisien pada desain filter FIR adalah window method dengan persamaan sebagai berikut: ${ }^{[1]}$

$$
h(n)=h_{D}(n) w(n)
$$

dengan $h_{D}(n)$ merupakan ideal impulse response.

High pass filter dari $\mathrm{h}_{\mathrm{D}}$ (n) memiliki persamaan berikut:

$$
h_{D}(n)=-2 f_{c} \frac{\sin \left(n \omega_{c}\right)}{n \omega_{c}}
$$

$\mathrm{w}(\mathrm{n})$ merupakan window function. Fungsi window umum yang digunakan untuk mendesain filter FIR adalah sebagai berikut ${ }^{[1]}$ :

Tabel 1. Common window function

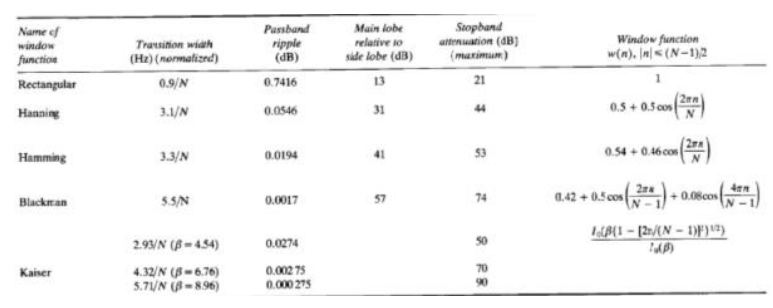

Pada artikel ini, akan digunakan hamming window karena sinyal input yang diterima pada proses filter memiliki amplitudo yang beragam dan fluktuatif. Oleh karena itu, rectangular window tidak digunakan karena low dynamic range dan hamming window sudah cukup untuk digunakan untuk digunakan sebagai filter ${ }^{[6]}$.

\section{Infinite Impulse Response - Pole Zero Placement Method dan Bilinear Transformation Method}

Filter IIR memiliki karakteristik non-linear, tidak stabil (karena memerlukan informasi dari impulse response sebelumnya), serta lebih kompleks dalam mengkonversi persamaan respons ke rangkaian. Oleh karena itu filter IIR lebih sering digunakan dalam filter digital atau dalam filter pemrograman.

Koefisien untuk desain suatu filter IIR menggunakan transfer function dengan persamaan sebagai berikut ${ }^{[1]}$ :

$$
H(z)=\frac{K(z-1)}{(z-\alpha)}
$$

Dengan:

$$
\alpha=\left\{\begin{array}{c}
1-2 \pi \frac{f_{c}}{f_{s}}, f_{c}<\frac{f_{s}}{4} \\
\pi-1-2 \pi \frac{f_{c}}{f_{s}}, f_{c}>\frac{f_{s}}{4}
\end{array}\right.
$$

Dari rangkaian perangkat keras (Gambar 2), dapat dilakukan filter IIR dengan mengubah rangkaian filter menjadi persamaan fungsi transfer laplace (persamaan 7), kemudian mengubah ke z-domain dengan bilinear transformation method (persamaan 6) sehingga menghasilkan persamaan z-transform pada persamaan $8^{[2]}$.

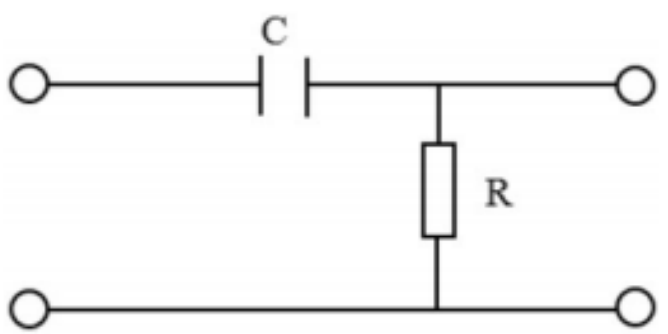


Gambar 2. Rangkaian highpass filter sederhana

$$
S=\frac{2}{T} \frac{z-1}{z+1}
$$

dengan $\mathrm{T}$ merupakan periode sampling.

\section{Signal to Noise Ratio (SNR)}

Dalam membuktikan keefektifan kedua filter dalam menghilangkan noise, SNR digunakan dengan persamaan sebagai berikut $^{[6]}$ :

$$
S N R=10 \log _{10} \frac{\text { output signal }}{\text { Input signal }}
$$

\section{Metodologi}

Dalam membandingkan keefektifan filter IIR dan filter FIR untuk menghilangkan atau meminimalisir noise sinyal ECG pada sinyal EMGdi, dilakukan empat tahap sebagai berikut:

1. Pada tahap pertama, menentukan puncak dari sinyal ECG pada sinyal EMGdi mentah.

2. Pada tahap kedua, memisahkan antara sinyal EMGdi yang terkontaminasi dengan sinyal ECG serta sinyal EMGdi murni dengan acuan puncak sinyal ECG yang telah didapatkan pada tahap pertama.

3. Pada tahap ketiga, sinyal EMGdi yang terkontaminasi dengan ECG akan dilakukan filtering. Filter FIR dibuat dengan window method sedangkan untuk filter IIR akan digunakan metode pole zero placement tetapi jika pendekatan melalui perangkat keras filter, dapat melalui metode bilinear transformation.

4. Pada tahap keempat, merekonstruksi sinyal EMGdi hasil filtering dengan sinyal EMGdi murni. Hasil sinyal output dengan dua jenis filter dibandingkan dari segi keefektifan menghilangkan sinyal noise ECG menggunakan SNR.

Tahapan-tahapan tersebut dilakukan menggunakan simulasi MATLAB.

\section{DATA DAN ANALISIS}

Pengolahan sinyal mentah, dilakukan sesuai dengan tahapan-tahapan melalui perangkat lunak MATLAB. Pengambilan data yang dilakukan pada jurnal [5] dilakukan selama 400 detik dengan interval pengambilan data 0,0005 detik. Pada artikel ini, akan mempersempit tampilan data selama 15 detik (Gambar 1) dengan tujuan kontaminasi ECG pada sinyal EMGdi dapat terlihat.

Sinyal mentah akan ditentukan puncak sinyal noise ECG (gambar 2) serta memisahkan antara sinyal EMGdi yang terkontaminasi dengan ECG dengan sinyal murni EMGdi berdasarkan puncak sinyal noise ECG yang telah terdeteksi dengan interval dari puncak sinyal $-0,1<\mathrm{t}<0.1$ dengan $\mathrm{t}$ adalah waktu (Gambar 3).

Sinyal murni EMGdi tidak akan melewati filter digital untuk menghindari terhilangnya sinyal informasi yang diperlukan. Sedangkan sinyal EMGdi yang terkontaminasi dengan ECG akan melewati filter FIR atau filter IIR dan akan dibandingkan keefektifan dari kedua filter tersebut.

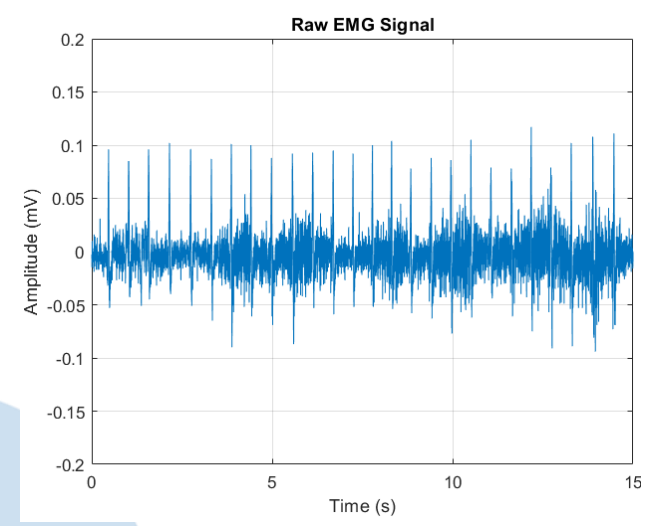

Gambar 2. Sinyal EMGdi mentah sebelum dilakukan filtering

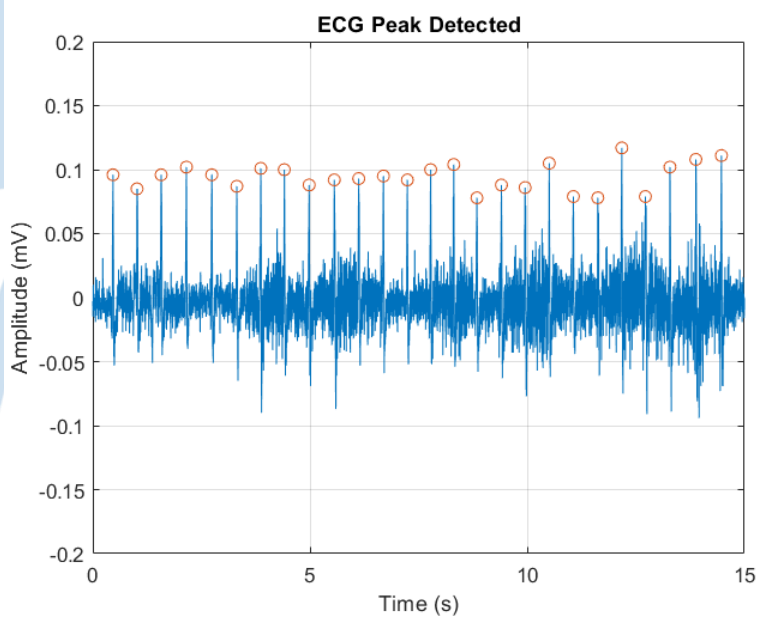

Gambar 3. Deteksi puncak sinyal noise ECG 

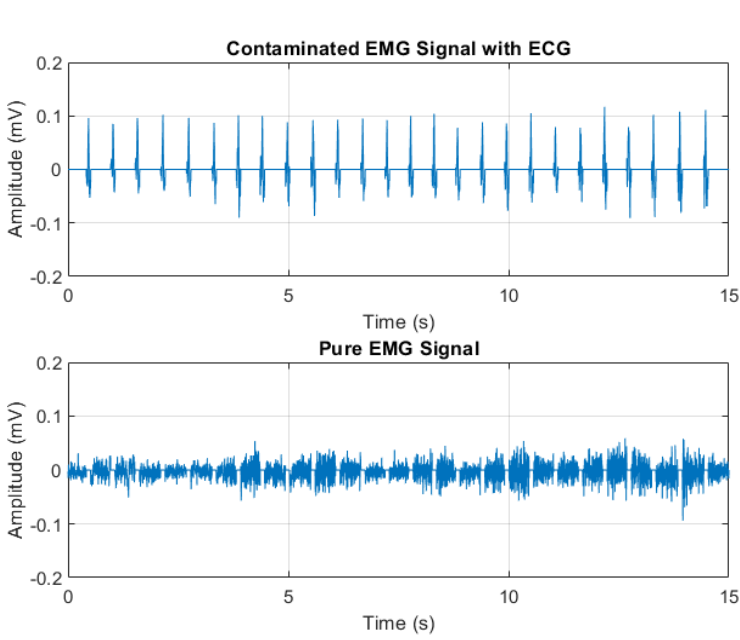

Gambar 4. Pemisahan sinyal EMGdi yang terkontaminasi ECG dan sinyal EMGdi yang murni

\section{A. Filter Sinyal Menggunakan Filter FIR}

Filter FIR akan dibentuk menggunakan metode window function dengan spesifikasi high pass filter sebagai berikut:

- $\quad$ Sampling frequency: $2 \mathrm{kHz}$

- Cut-off frequency: $50 \mathrm{~Hz}$

- Passband attenuation: $>50 \mathrm{~dB}$

- $\quad$ Transition width: $1 \mathrm{~Hz}$

Dari spesifikasi yang ditentukan tersebut, maka digunakanlah hamming window dengan panjang filter 6600 dan orde filter sebesar 46. Penentuan orde filter berdasarkan [4] sudah cukup untuk diaplikasikan pada peralatan medis.
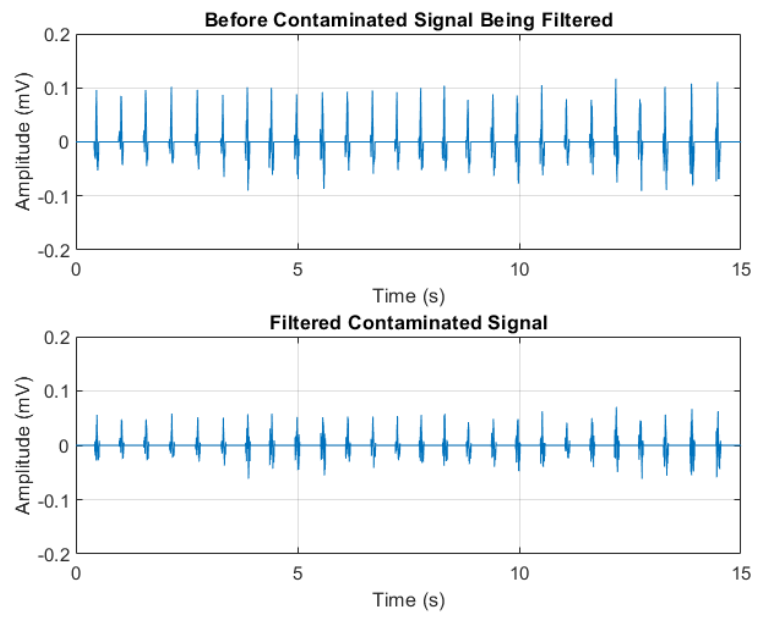

Gambar 5. Perbandingan sinyal noise ECG sebelum dilakukan filter FIR (atas) dan sesudah dilakukan filter FIR (bawah)
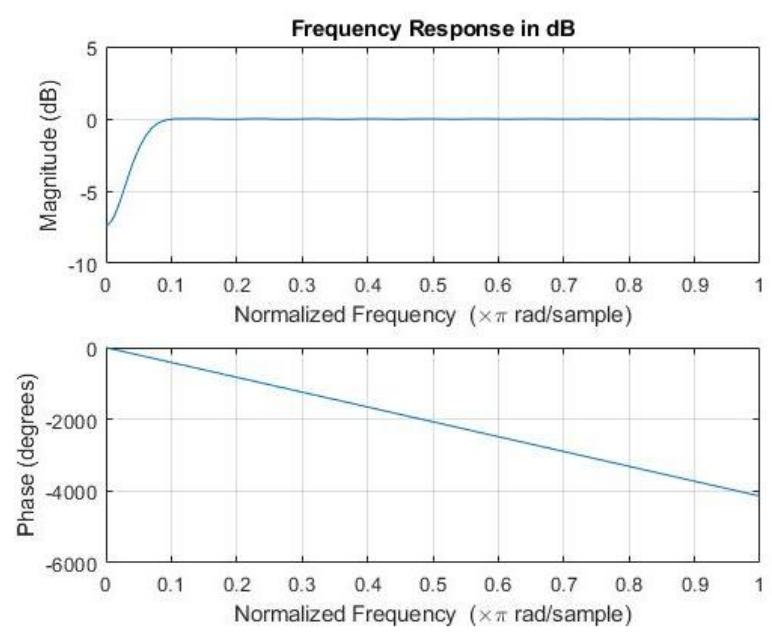

Gambar 6. Respon frekuensi dari high pass filter FIR

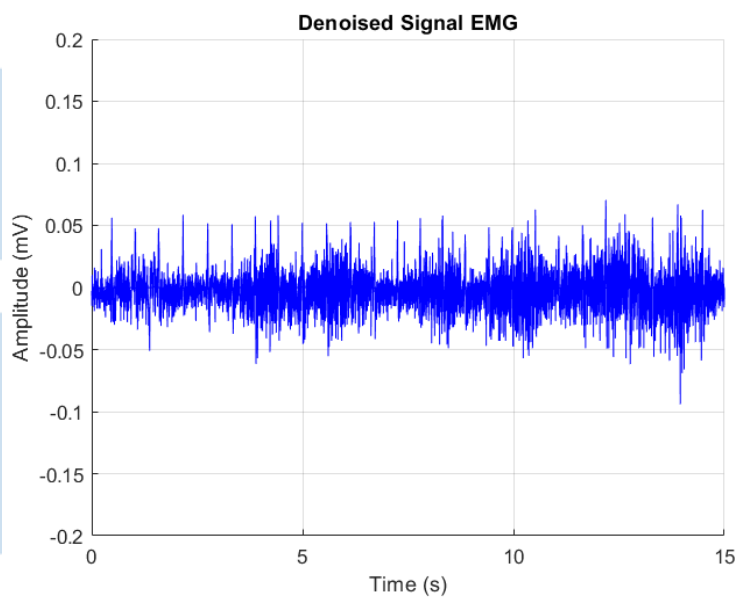

Gambar 7. Hasil rekonstruksi sinyal EMGdi yang sudah dilakukan filter FIR dengan sinyal EMGdi murni

\section{B. Filter Sinyal Menggunakan Filter IIR}

Persamaan laplace dari rangkaian high pass filter sederhana (Gambar 2) adalah sebagai berikut:

$$
H(s)=\frac{R}{\frac{1}{s C}+R}
$$

$\mathrm{R}$ adalah resistansi elektrik dan $\mathrm{C}$ adalah kapasitansi. Dengan menggunakan metode bilinear transformation pada persamaan 6 , maka persamaan 7 menghasilkan persamaan transfer fungsi domain $\mathrm{z}$ :

$$
H(z)=\frac{2 R C(z-1)}{T(z+1)+2 R C(z-1)}
$$

Pendekatan high pass filter (Gambar 2) yang digunakan diasumsikan memiliki resistansi $1 \Omega$ dan cut-off frequency $50 \mathrm{~Hz}$ sehingga nilai kapasitansi bernilai 0,0032 C. Dengan periode sampling 0,0005 detik, maka substitusi nilai ke persamaan Z-transform menghasilkan persamaan sebagai berikut: 


$$
H(z)=\frac{z-1}{1,078 z-0,922}
$$

Hasil filter dengan input sinyal mentah (Gambar 2) menghasilkan sinyal keluaran seperti pada Gambar 8 .
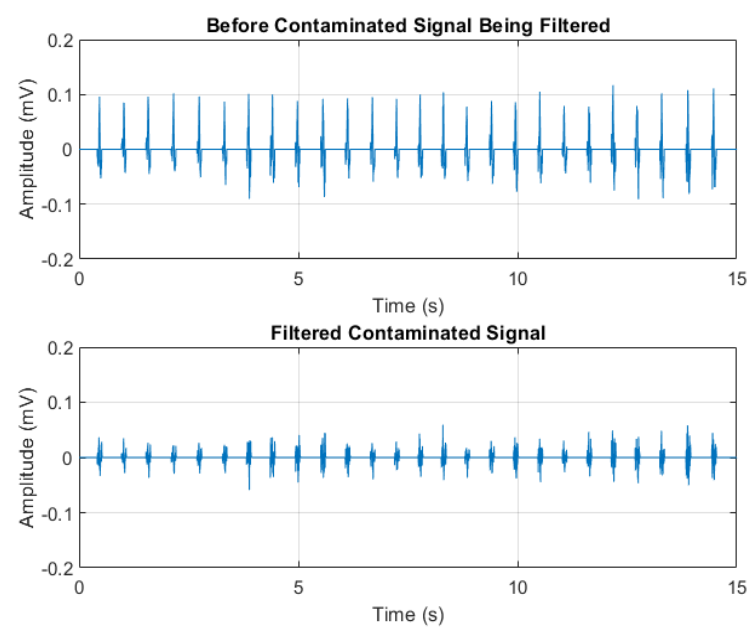

Gambar 8. Perbandingan sinyal noise ECG sebelum dilakukan filter IIR (atas) dan sesudah dilakukan filter IIR (bawah)
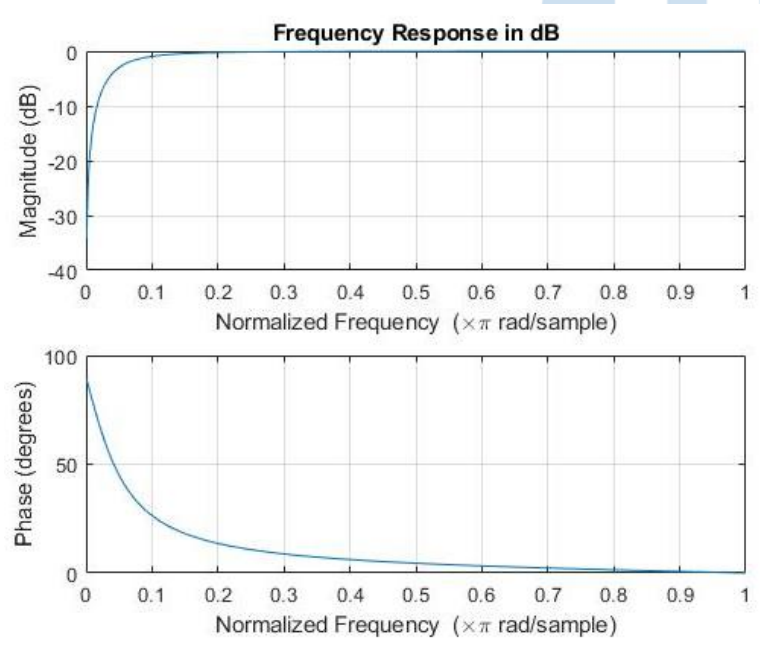

Gambar 9. Respon frekuensi dari high pass filter IIR

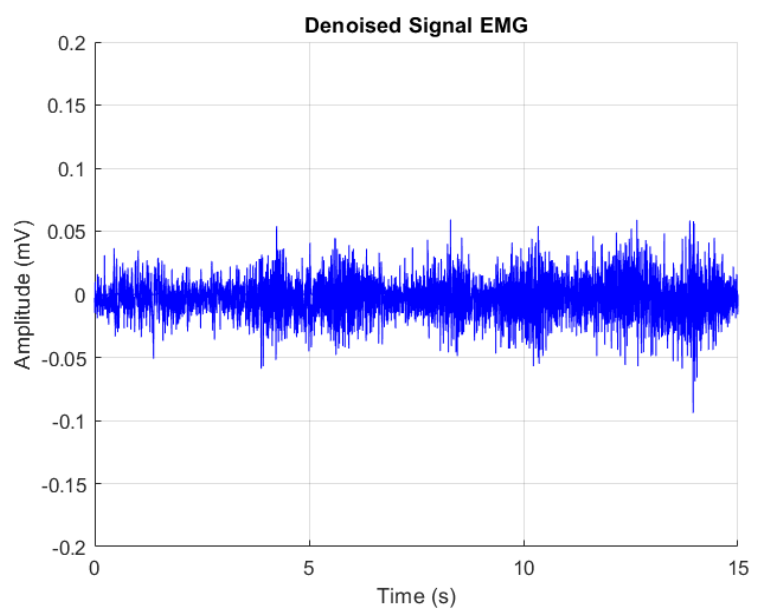

Gambar 10. Hasil rekonstruksi sinyal EMGdi yang sudah dilakukan filter IIR dengan sinyal EMGdi murni

\section{Evaluasi}

Sinyal input disaring menggunakan filter FIR dan filter IIR. Dari hasil filter sinyal tersebut, menghasilkan sinyal keluaran (Gambar 7 dan Gambar 10). Berdasarkan keefektifan filter dengan menggunakan SNR, terlihat bahwa filter FIR memiliki nilai yang lebih besar daripada filter IIR (Gambar 11 dan 13). SNR bernilai negatif menunjukkan noise dari sinyal ECG lebih besar daripada sinyal pernapasan EMGdi. Sedangkan dari segi execution time pada proses FIR filter dan IIR filter berlangsung selama 0.014522 detik dan 0.018817 detik secara berurutan. Dari kedua jenis filter yang digunakan, untuk mereduksi sinyal noise ECG pada sinyal pernapasan EMGdi, FIR filter dengan menggunakan window method sudah mampu menghasilkan output sinyal yang baik dengan SNR lebih besar dan waktu eksekusi yang lebih cepat dengan perbedaan \pm 0.004 detik. Sedangkan dari kestabilan filter, filter FIR (Gambar 12) dan filter IIR (Gambar 13) menunjukkan sistem stabil karena lokasi pole yang berada di dalam area lingkar.

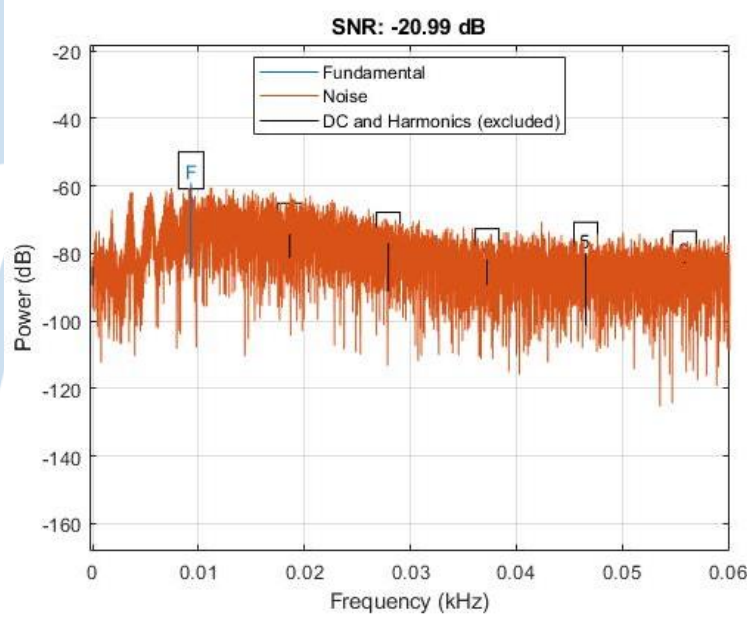

Gambar 11. SNR dari hasil sinyal yang difilter oleh FIR 


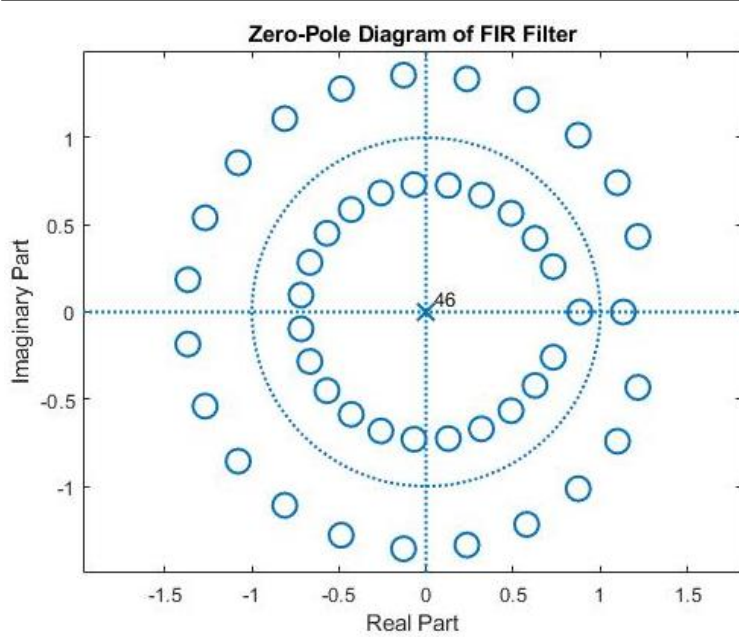

Gambar 12. Kestabilan filter FIR

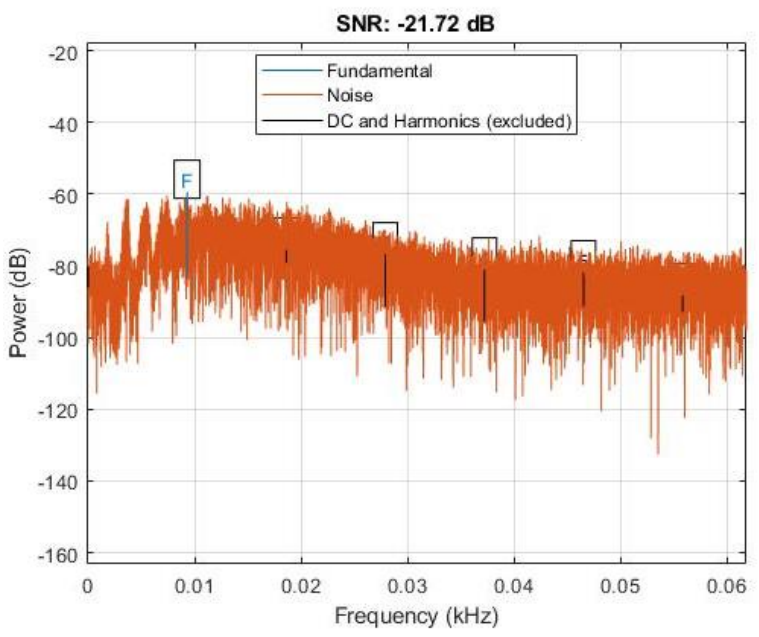

Gambar 13. SNR dari hasil sinyal yang difilter oleh IIR

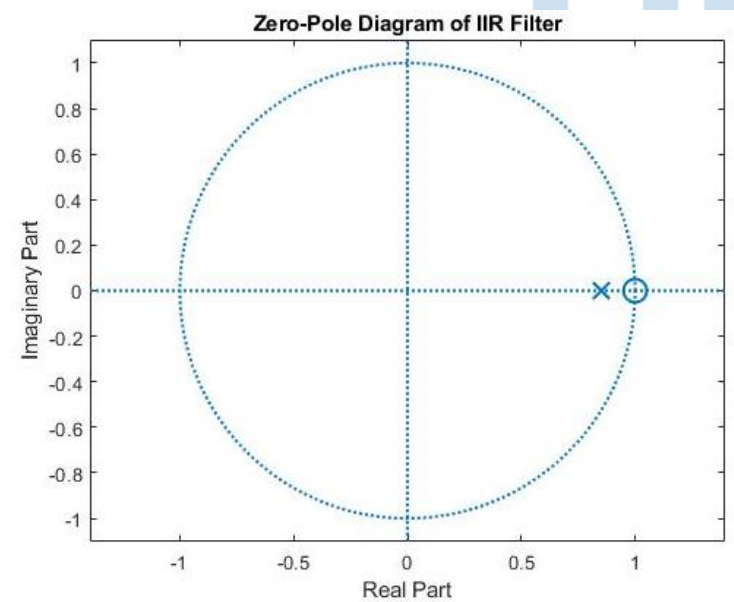

Gambar 14. Kestabilan filter IIR

\section{SimPULAN}

Penelitian yang telah dilakukan dengan menggunakan filter IIR dengan pendekatan bilinear transformation pada pengaplikasian pengukuran sinyal EMGdi pada [2] kurang tepat digunakan karena memiliki SNR yang lebih kecil daripada filter FIR. Selain itu execution time pada filter FIR lebih cepat dan sistem menunjukkan respon yang stabil. Oleh karena itu, dalam mereduksi sinyal ECG pada sinyal EMGdi dapat menggunakan filter FIR dengan metode window.

\section{DAFTAR PUSTAKA}

[1] Ifeachor, E. C., \& Jervis, B. W. (2002). Digital signal processing: a practical approach. Essex: Addison Wesley.

[2] Luo, G. (2018). A MATLAB-based biomedical signal de-noising applied to digital signal processing course for third-year students. International Journal of Electrical Engineering \& Education 56(1), 51-61. doi: $10.1177 / 0020720918780843$.

[3] Padmavathy, T., Saravanan, S. \& Vimalkumar, M., 2020. Partial product addition in Vedic design-ripple carry adder design fir filter architecture for electro cardiogram (ECG) signal de-noising application. Microprocessors and Microsystems, 76, p.103113.

[4] Sumalatha, M., Naganjaneyulu, P. \& Prasad, K.S., 2019. Low power and low area VLSI implementation of vedic design FIR filter for ECG signal de-noising. Microprocessors and Microsystems, 71, p.102883.

[5] Biagetti, G., Carnielli, V. P., Crippa, P., Falaschetti, L., Scacchia, V., Scalise, L., \& Turchetti, C. (2019). Dataset from spirometer and sEMG wireless sensor for diaphragmatic respiratory activity monitoring. Data in Brief, 25, 104217. doi: 10.1016/j.dib.2019.104217.

[6] Tan, L., \& Jiang, J. (2019). Digital signal processing: fundamentals and application (3rd ed.). London: Academic Press, an imprint of Elsevier. 